\title{
Case review: food pattern effects on milk lipid profiles
}

\begin{abstract}
It has been shown that maternal food intake determines the levels of unsaturated fatty acids that are present in human milk. This case study compares the human milk lipid profiles the first two weeks of lactation from women consuming three food patterns: vegan, standard American diet, and Asian. Participants were matched for demographics. The milk samples were analyzed using gas chromatography to determine the lipid profile for each participant. The lipid profiles differed by food pattern $(\mathrm{p}<0.007)$. Linoleic acid and alpha-linolenic acid levels were highest for the vegan food pattern. The ratios of omega- 6 to omega- 3 fatty acids were well above the suggested ratio considered to be optimal with the vegan pattern had the lowest omega- 6 to omega- 3 ratio and the highest level of docosahexaenoic acid, possibly indicating conversion of alpha-linoleic acid to docosahexaenoic acid. Further research is needed to determine the impact this may have on long-term infant health.
\end{abstract}

Keywords: food patterns, breastfeeding, fatty acid in human milk, maternal diet, docosahexaenoic acid, human milk composition, lactation, nutrition
Volume 8 Issue 6 - 2018

\author{
Darby Dickton,' Jimi Francis ${ }^{2}$ \\ 'University of California, Davis Medical Center, USA \\ ${ }^{2}$ College of Nursing and Health Sciences, University of Texas at \\ Tyler, USA
}

Correspondence: Jimi Francis, College of Nursing and Health Sciences, University of Texas at Tyler, 3900 University Blvd,Tyler, TX 75799, USA, Fax +903-566-7065, Tel + 903-565-5522, Email jframcis@uttyler.edu

Received: November 05, 2018 | Published: November 26, 2018

\section{Introduction}

For infants being exclusively breastfed, human milk is their only source of nutrients with the lipid component of human milk as major source of energy for breastfed infants. Lipids contribute approximately half of the total energy intake infants need. ${ }^{1}$ In human milk during early infant development, these lipids are critical for growth and maturation ${ }^{2}$ in both the short and long term. ${ }^{3}$ It is known that the essential fatty acids, linoleic acid (LA), an omega- 6 fatty acid, and alpha-linolenic acid (ALA), an omega-3 fatty acid are reflective of food intake in the human body. ${ }^{4-6}$ While omega- 6 and omega- 3 fatty acids transfer to human milk based on maternal diet, very little is converted to longer chain fatty acids such as arachidonic acid (ARA) (converted from LA) and docosahexaenoic acid (DHA) (converted from ALA). ${ }^{7}$ It is unknown whether the fatty acids docosahexaenoic acid (DHA), eicosapentaenoic acid (EPA), and arachidonic acid (AA) in human milk are reflective of maternal dietary pattern. Little information is available regarding the day-to-day changes in the lipid profile of human milk in the first few days postpartum with relation to different dietary patterns. The objective of this case study was to evaluate the lipid profile for three dietary patterns during the first two weeks postpartum: Vegan, Standard American, and Asian dietary patterns.

\section{Methods}

The participants were a convenience sample selected from a larger study of women attending prenatal breastfeeding classes. The participants were chosen based on their self-reported food patterns and matched in demographics to compare lipid profiles based on dietary considerations. All procedures were reviewed, approved, and monitored by the University Institutional Review Board. The participants were recruited during the third trimester of pregnancy. The participants were English speaking healthy women giving birth to healthy full-term infants who were planning to breastfeed their infants exclusively for 6months. Each participant received lactation management prenatally and immediately postpartum from an
Internationally Board Certified Lactation Consultant to ensure that any breastfeeding challenges were addressed immediately. Each infant was weighed beginning on day 3 postpartum using a Tanita Baby-Weigh scale at each milk sample collection to verify appropriate weight gain and ensure non-inference with infant feeding. Three women fit the desired dietary profile: Vegan (VGN), standard American diet (SAD), and Asian (ASN). A food frequency questionnaire was completed for each participant during their pregnancy to identify the dietary pattern. A food recall was conducted during the first week postpartum to confirm the dietary pattern identified during pregnancy for each participant.

Beginning on Day 3 postpartum and continuing through Day 12, a milk sample of approximately 3 milliliters was collected from each participant daily using hand expression at the end of the feeding. The samples were collected at approximately the same time each day within a two-hour window. The milk sample was collected consistently from the right breast. Upon collection, the sample was placed in a foil-lined, insulated bag containing cold packs for transport to the laboratory. At the lab, the sample was divided into three 1-ml aliquots and stored at $-80^{\circ} \mathrm{C}$ until analysis. Two of the aliquots of milk were analyzed using the gas chromatography (GC) analysis of fatty acid methyl esters (FAME) protocol detailed by Cruz-Hernandez et al. ${ }^{7}$ The FAME concentrations were calculated by multiplying the peak area of the fatty acid by its formula weight and by nmole of 19:0 internal standard present per unit area. The third aliquot of milk was analyzed for protein using the Lowry based method of the BioRad DC Assay to standardize the nmole of FAME in the sample to the milligrams of protein. The fatty acids of interest were linoleic acid, C18:2n-6 (LA); $\alpha$-linolenic acid, C18:3n-3 (ALA); arachidonic acid, C20:4n-6 (ARA); eicosapentaenoic acid, C20:5n-3 (EPA); and Docosahexaenoic Acid C22:6n-3 (DHA). Oleic and Palmitoleic acids were included in the analysis.

\section{Results}

While the dietary patterns were different, the participants were in 
good health, living within a 5-mile radius (in the same community with the same access to resources), were of the same socioeconomic status, married, had pre-pregnancy BMI of 24, gained between 25 to 30 pounds during their pregnancy, and were primiparas. All three women consumed the same brand of multi-vitamin and mineral prenatal supplement during their pregnancy and discontinued the supplement at the birth of their infant, except for the VGN who continued to take a B12 supplement. Additionally, they all intended to breastfeed their infants for at least six months. The VGN and SAD were Caucasian. The ASN was Korean. The VGN pattern was characterized by abstaining from the use of any animal products and consuming foods that contain no animal products of any kind. The SAD had food patterns characterized by high intake of red meat, processed meat, prepared foods, saturated fats, fried foods, dairy products, high-fructose corn syrup, eggs, refined grain products, potatoes, and sweetened beverages. The ASN pattern was predominantly based on plant foods including rice, a wide variety of vegetables, and fresh fruit with small portions of lean meat and fish. The 24-hour food recall is summarized in Table 1 . The daily values and means $(+\mathrm{SD})$ for each fatty acid measured in the milk are shown for each food pattern in Table 2.

Table I 24hour Food Recall

\begin{tabular}{|c|c|c|c|c|c|}
\hline Food Pattern & Breakfast & Lunch & Snack & Dinner & Snack \\
\hline VGN & $\begin{array}{l}\text { Breakfast burrito (flour tortilla with } \\
\text { pinto beans, rice, and vegetables in a } \\
\text { mild Mexican sauce), a tangerine, and } \\
\text { I cup low-fat non-dairy milk }\end{array}$ & $\begin{array}{l}\text { Brown rice with vegetables } \\
\text { and one cup of carrot sticks } \\
\text { with ranch dressing. }\end{array}$ & $\begin{array}{l}3 / 4 \text { ounce almonds } \\
\text { and raisins }\end{array}$ & $\begin{array}{l}\text { Black bean enchilada } \\
\text { with a mixed salad with } \\
\text { raspberry vinaigrette }\end{array}$ & Peach \\
\hline SAD & $\begin{array}{l}\text { Scrambled eggs with cheese and } \\
\text { cranberry juice. }\end{array}$ & $\begin{array}{l}\text { Hamburger on a bun with } \\
\text { lettuce tomato, pickles, } \\
\text { mayonnaise, and mustard. } \\
\text { Coke }\end{array}$ & $\begin{array}{l}\text { Yogurt with } \\
\text { blueberries. }\end{array}$ & $\begin{array}{l}\text { Macaroni and cheese } \\
\text { with cooked broccoli. }\end{array}$ & $\begin{array}{l}\text { Coke and } \\
\text { potato chips }\end{array}$ \\
\hline ASN & $\begin{array}{l}\text { Pho soup, made of rice noodles, beef, } \\
\text { and beef broth seasoned with star } \\
\text { anise, cinnamon sticks, cloves and } \\
\text { ginger. Served with sprouts, basil, } \\
\text { other herbs, and lime wedges. }\end{array}$ & $\begin{array}{l}\text { Chicken pot sticker, ginger } \\
\text { soy dip, and stir fried spicy } \\
\text { eggplant with brown rice }\end{array}$ & $\begin{array}{l}\text { Spring rolls with } \\
\text { chili-lime dip. }\end{array}$ & $\begin{array}{l}\text { Seared salmon, fried } \\
\text { rice, papaya salad with } \\
\text { chili vinaigrette. }\end{array}$ & Edamame \\
\hline
\end{tabular}

Table 2 Daily concentration of fatty acids for day 3 through day 12 postpartum by food pattern

\begin{tabular}{|c|c|c|c|c|c|c|c|c|c|c|c|}
\hline & Day 3 & Day 4 & Day 5 & Day 6 & Day 7 & Day 8 & Day 9 & Day I0 & Day I I & Day I2 & Mean(+SD) \\
\hline \multicolumn{12}{|l|}{ VGN } \\
\hline Palmitoleic Acid CI6:In-7 & 10.99 & 10.18 & 8.27 & 10.53 & 7.64 & 10.38 & 15.59 & 10.75 & 7.19 & 4.82 & $9.63(2.9)$ \\
\hline Oleic Acid CI8:In-9 & 2.01 & $2.4 I$ & 2.31 & 2.93 & 3.38 & 3.3 & 3.29 & 3.56 & 2.68 & 1.58 & $2.74(0.66)$ \\
\hline Linoleic Acid CI 8:2n-6 & 33.57 & 36.9 & 27.99 & 20.72 & 23.27 & 26.49 & 25.29 & 40.93 & 31.94 & 24.51 & $29.16(6.47)$ \\
\hline$\alpha$-Linolenic Acid C I8:3n-3 & 2.09 & 1.86 & 2.18 & 1.22 & 2.74 & 2.4 & 7.55 & 3.51 & 3.4 & 1.97 & $2.89(1.78)$ \\
\hline Arachidonic Acid C20:4n-6 & 0.6 & 0.7 & 0.8 & 0.57 & 0.55 & 0.85 & 0.92 & 0.65 & 0.9 & 0.59 & $0.7 I(0.14)$ \\
\hline $\begin{array}{l}\text { Eicosapentaenoic Acid } \\
\text { C20:5n-3 }\end{array}$ & 0.4 & 0.14 & 0.18 & 0.15 & 0.14 & 0.09 & 0.15 & 0.16 & 0.29 & 0.16 & $0.19(0.09)$ \\
\hline $\begin{array}{l}\text { Docosahexaenoic Acid } \\
\text { C22:6n-3 }\end{array}$ & 0.64 & 0.54 & 0.58 & 0.54 & 0.5 & 0.55 & 0.59 & 0.36 & 0.62 & 0.47 & $0.54(0.08)$ \\
\hline Total & 50.3 & 52.73 & 42.3 & 36.67 & 38.22 & 44.04 & 53.37 & 59.92 & 47.01 & 34.09 & 45.87 \\
\hline \multicolumn{12}{|l|}{ SAD } \\
\hline Palmitoleic Acid CI6:In-7 & 12.29 & 13.1 & 11.99 & 10.35 & 10.98 & 13.75 & 15.43 & 7.03 & 10.1 & 13.05 & | I.8I(2.33) \\
\hline Oleic Acid CI 8: In-9 & 3.35 & 3.51 & 3.49 & 3.65 & 3.02 & 3.83 & 4.65 & 2.14 & 3.4 & 4.1 & $3.5 I(0.66)$ \\
\hline a-Linolenic Acid CI8:3n-3 & 0.94 & 1.34 & 0.86 & 0.98 & 1.4 & 1.36 & 1.54 & 0.99 & 1.27 & 2.91 & $\mathrm{I} .36(0.59)$ \\
\hline Arachidonic Acid C20:4n-6 & 0.72 & 0.86 & 0.64 & 1.11 & 0.91 & 1.01 & 0.82 & 1.02 & 1.11 & 1.12 & $0.93(0.17)$ \\
\hline $\begin{array}{l}\text { Eicosapentaenoic Acid } \\
\text { C20:5n-3 }\end{array}$ & 0.08 & 0.09 & 0.03 & 0.07 & 0.07 & 0.06 & 0.09 & 0.08 & 0.53 & 0.69 & $0.18(0.23)$ \\
\hline $\begin{array}{l}\text { Docosahexaenoic Acid } \\
\text { C22:6n-3 }\end{array}$ & 0.26 & 0.34 & 0.26 & 0.44 & 0.32 & 0.37 & 0.32 & 0.24 & 0.44 & 0.31 & $0.33(0.07)$ \\
\hline Total & 33.37 & 40.72 & 31.75 & 34.27 & 35.81 & 42.4 & 38.69 & 26.88 & 44.52 & 49.41 & 37.78 \\
\hline \multicolumn{12}{|l|}{ ASN } \\
\hline Palmitoleic Acid CI6:In-7 & 9.65 & 14.33 & 10.68 & 8.98 & 8.61 & $13.4 \mid$ & 8.56 & 8.12 & 5.65 & 7.25 & $9.52(2.66)$ \\
\hline Oleic Acid CI8:In-9 & 1.49 & $\mathrm{I} .87$ & 1.9 & 1.58 & 1.19 & 19.43 & 1.49 & 2.3 & 1.12 & 1.13 & $3.35(5.66)$ \\
\hline Linoleic Acid CI 8:2n-6 & $11.7 \mid$ & 10.61 & 12.58 & 9.19 & 11.96 & 18.28 & 13.25 & 16.32 & 9.46 & 16.73 & $13.01(3.14)$ \\
\hline a-Linolenic Acid CI8:3n-3 & I.II & 0.63 & 0.74 & 0.51 & 1.04 & 0.35 & 0.9 & 1.09 & 0.46 & $\mathrm{I}$ & $0.78(0.28)$ \\
\hline Arachidonic Acid C20:4n-6 & 0.43 & 0.26 & 0.66 & 0.44 & 0.56 & 0.43 & 0.56 & 0.54 & 0.39 & 0.47 & $0.47(0.11)$ \\
\hline $\begin{array}{l}\text { Eicosapentaenoic Acid } \\
\text { C20:5n-3 }\end{array}$ & 0.03 & 0.06 & 0.07 & 0.06 & 0.07 & 0.04 & 0.07 & 0.07 & 0.04 & 0.05 & $0.06(0.01)$ \\
\hline Total & 24.82 & 29.34 & 27.04 & 21.06 & 23.82 & 52.01 & 25.24 & 28.66 & 17.35 & 26.77 & 27.61 \\
\hline
\end{tabular}


to omega-3 ratios in human milk in relation to changes in maternal food patterns as there are no solid conclusions about the optimal lipid profile for long-term infants' health. ${ }^{14}$

\section{Funding details}

This study was funded by a gift from the Foundation for Maternal, Infant, and Lactation Knowledge.

\section{Acknowledgments}

Thank you to all the women that kindly donated their time and their milk for this study.

\section{Conflicts of interest}

Authors declare that there is no conflicts of interest.

\section{References}

1. Koletzko B. Human Milk Lipids. Ann Nutr Metab. 2016;69(Supp 2):28-40.

2. Andreas NJ, Kampmann B, Mehring Le-Doare K. Human breast milk: A review on its composition and bioactivity. Early Hum Dev. 91(11):629-635.

3. Delplanque B, Gibson R, Koletzko B, et al. Lipid Quality in Infant Nutrition: Current Knowledge and Future Opportunities. J Pediatr Gastroenterol Nutr. 2015;6(1):8-17.

4. Alvheim AR, Malde MK, Osei-Hyiaman D, et al. Dietary linoleic acid elevates endogenous 2-AG and anandamide and induces obesity. Obesity (Silver Spring). 2012;20(10):1984-1994.

5. Raatz SK, Conrad Z, Johnson L, et al. Relationship of the Reported Intakes of Fat and Fatty Acids to Body Weight in US Adults. Nutrients.
2017;9(5): pii E438.

6. Innis SM. Human milk: Maternal dietary lipids and infant development. Proceedings of the Nutrition Society. 2007;66(3):397-404.

7. Cruz-Hernandez C, Goeuriot S, Giuffrida F, et al. Direct quantification of fatty acids in human milk by gas chromatography. $J$ Chromatogr A. 1284:174-179.

8. Simopoulos AP. Omega-6/omega-3 essential fatty acids: biological effects.World Rev Nutr Diet. 2009;99:1-16.

9. Simopoulos AP. The Importance of the Omega-6/Omega-3 Fatty Acid Ratio in Cardiovascular Disease and Other Chronic Diseases. Exp Biol Med (Maywood). 2008;233(6):674-688.

10. Clark KJ, Makrides M, Neumann MA, et al. Determination of the optimal ratio of linoleic acid to alpha-linolenic acid in infant formulas. J Pediatr. 1992;120(4 Pt 2):S151-58.

11. Kim H, Kang S, Jung BM, et al. Breast milk fatty acid composition and fatty acid intake of lactating mothers in South Korea. Br J Nutr. 2017;117(4):556-561.

12. Innis SM. Impact of maternal diet on human milk composition and neurological development of infants. Am $J$ Clin Nutr. 2014;99(3):734S-41S.

13. Keikha M, Bahreynian M, Saleki M, et al. Macro- and Micronutrients of Human Milk Composition: Are They Related to Maternal Diet? A Comprehensive Systematic Review. Breastfeed Med. 2017;12(9):517527.

14. Demmelmair H, Koletzko B. Importance of fatty acids in the perinatal period. World Rev Nutr Diet. 2015;112:31-47. 